\title{
CURSO PARA A FORMAÇÃO HISTÓRICO-POLÍTICA NA GRADUAÇÃO EM SAÚDE: ANÁLISE DE UMA CONSTRUÇÃO PARTILHADA
}

\author{
HISTORICAL AND POLITICAL EDUCATION COURSE FOR UNDERGRADUATE \\ HEALTH STUDENTS: ANALYSIS OF A SHARED CONSTRUCTION
}

\section{CURSO PARA LA FORMACIÓN HISTÓRICO-POLÍTICA EN LA GRADUACIÓN \\ EN SALUD: ANÁLISIS DE UNA CONSTRUCCIÓN COMPARTIDA}

\author{
Helena Maria Scherlowski Leal David ${ }^{1}$ \\ Jose Augusto Pina ${ }^{2}$ \\ Eduardo Navarro Stotz ${ }^{3}$ \\ Ivo Aurélio Lima Júnior ${ }^{4}$ \\ Laíra Augusta Viegas Vasconcellos ${ }^{5}$ \\ Leonardo Vidal Mattos ${ }^{6}$ \\ Lucas Bronzatto Silveira ${ }^{7}$ \\ Norhan Sumar ${ }^{8}$
}

Resumo A graduação universitária das áreas da saúde vem sendo debatida quanto às necessidades de mudanças curriculares em torno dos princípios do Sistema Único de Saúde, entre outros temas. Dentre os desafios apontados, está o da superação da formação tecnicista e operacional e a ampliação da capacidade de reflexão crítica do aluno sobre as determinações históricas e políticas da saúde. O texto analisa o processo ensino-aprendizagem numa perspectiva crítica a partir do curso para a Formação Histórica e Política de Estudantes de Graduação das Áreas da Saúde, atividade extensionista desenvolvida na modalidade semipresencial em nível nacional, apoiada pela Política Nacional de Educação Popular em Saúde no Sistema Único de Saúde. No presente artigo, foi analisada a experiência vivenciada no curso ocorrido de março a dezembro de 2014. O desenvolvimento do curso apoiou-se na concepção teórica e metodológica da construção compartilhada do conhecimento, orientada pelo campo da Educação Popular e Saúde. O artigo apresenta: histórico e processo de construção do curso, projeto político-pedagógico, material didático-pedagógico e contribuições e questões, com apontamentos sobre potenciais desdobramentos futuros em processos formativos na área da saúde.

Palavras-chave formação em saúde; trabalho em saúde; projeto político-pedagógico; diretrizes curriculares; sociedade e saúde.
Abstract Undergraduate studies in the fields of health are currently being debated regarding the need for change in their syllabuses concerning the principles of the Brazilian Unified Health System, among other topics. Overcoming the operational and technicist education and expanding the critical thinking abilities of the students about the historical and political determinations of health are among the challenges highlighted. The article analyzes the teaching/learning process with a critical perspective based on the Historical and Political Education Course for Undergraduate Health Students, an extension semi-virtual course offered nationally, and supported by the National Policy for Popular Education in Health within the Unified Health System. In the present article, we analyzed the experiences brought about by the course, which took place between March and December 2014. The development of the course was based on the theoretical and methodological conceptions of the construction of shared knowledge, guided by the field of Popular Education and Health. The article presents: the history and the process of development of the course, the political and pedagogical project, the educational and pedagogical materials, and the contributions and questions, with notes on the potential future implications in educational processes in the field of health.

Keywords education in health; work in health; political and pedagogical project; syllabus guidelines; society and health. 


\section{Introdução}

A formação profissional do futuro trabalhador de saúde, assim como o próprio campo da atenção à saúde, é arena de disputa entre projetos diversos, que expressam múltiplas visões de mundo e sociedade. No marco da implementação do Sistema Único de Saúde (SUS) no Brasil, os princípios que norteiam a ideia de uma política setorial pública e de caráter universalista impuseram discussões também para a área da formação profissional em saúde. Esses debates transformaram-se em programas de integração entre serviços, universidades, a exemplo do Programa de Educação pelo Trabalho para a Saúde, PET-Saúde (Brasil, 2010). Além disso, propiciaram mudanças nas Diretrizes Curriculares Nacionais (DCN) dos cursos de graduação das áreas da saúde (Fernandes et al., 2013).

A ideia de articular e integrar os conteúdos e práticas pedagógicas com o mundo do trabalho já durante a formação está presente na Lei Orgânica da Saúde (Brasil, 1990), quando afirma que o SUS é o ordenador da formação de recursos humanos para o setor saúde. No entanto, as tensões entre uma formação de caráter técnico-científico, organizada em currículos tradicionais de base flexneriana, ${ }^{9}$ considerados superados, e modelos de formação inovadores, que visam integrar áreas de conhecimento e ampliar a capacidade reflexiva do estudante, continuam a ser um desafio nos dias de hoje (Araújo, Miranda e Brasil, 2007).

O conhecimento acerca dos determinantes históricos e políticos da formação social brasileira, ainda que destacado como área relevante em alguns currículos, acaba abreviado diante do conhecimento e das habilidades técnicocientíficas específicas, os chamados 'núcleos duros' da formação em saúde. Os momentos e conteúdos de formação política, dentro da estrutura curricular, possuem pouco espaço e capacidade de modulação frente à realidade. A atividade extensionista é uma exceção por força da prática extramuros e convoca o graduando a interagir com a realidade; entretanto, tal prática depende da condução feita de forma reflexiva pelo professor-orientador. Caso contrário, a atividade extensionista corre o risco de ser apenas 'mais uma entre tantas outras', sem sentido formativo crítico e sujeita a cair no assistencialismo.

Assim, o professor que busca formar o futuro profissional de saúde dentro de uma concepção de práxis, para além de apenas garantir o aporte de recursos humanos tecnicamente habilitados, pode se sentir frustrado diante da grade curricular plena e o cotidiano intensivo de aulas e estágios. A busca por alternativas que colaborem para uma formação integral é algo apontado como fundamental para dar sentido ao ensino universitário (Araújo, Miranda e Brasil, 2007; Vilela e Mendes, 2003). 
Com a possibilidade de apoio a ações de comunicação e formação de Educação Popular em Saúde pelo Ministério da Saúde, por meio da sua Secretaria da Gestão Estratégica e Participativa em Saúde (MS-SGEP), surgiu a oportunidade, em 2012, para a elaboração de um curso para a Formação Histórica e Política de Estudantes de Graduação das Áreas da Saúde - Curso FHP.

Os processos de elaboração e implementação deste curso constituem o objeto deste artigo. Estes processos foram registrados por meio de relatórios parciais e final, registros de reuniões e oficina de avaliação, tanto escritos como em vídeo, tendo todos os autores do artigo participado das etapas do curso.

O presente artigo analisa aspectos do Curso FHP, no que tange à concretização dos objetivos de ensino-aprendizagem críticos e quanto aos seus desafios e dificuldades, como forma de compartilhar e subsidiar novos aprendizados e processos formativos similares na área da Saúde. Além desta introdução, o texto está organizado em quatro tópicos. O primeiro intitula-se Histórico e processo de construção do Curso FHP. O segundo discorre sobre o Projeto Político-Pedagógico, no qual são assinalados os objetivos, metodologia e programa de estudos do Curso FHP. O terceiro tópico refere-se ao material didático-pedagógico. Por fim, o último apresenta as contribuições e questões trazidas pelo curso, sua problematização e apontamentos sobre potenciais desdobramentos futuros.

\section{Histórico e processo de construção do Curso FHP}

Desde 2003, grupos e coletivos que trabalhavam temas de Educação Popular e Saúde (EPS) foram se articulando em eventos e atividades diversas, configurando-se como um campo de fazeres e práticas apoiado institucionalmente pelo Ministério da Saúde, numa ótica de fortalecer os processos de participação popular no SUS. Com o avançar dos anos, no entanto, ficou cada vez mais claro que era preciso propor atividades articuladas aos processos institucionais, que permitissem a disseminação dos conhecimentos e práticas de EPS para os estados e municípios. Além disso, a EPS, como perspectiva de abordagem e ação coletiva no enfrentamento das questões de saúde, fortaleceu-se também no âmbito da produção acadêmica. As pesquisas e projetos de extensão pautados por pressupostos de diálogo entre saberes do senso comum e científicos, de respeito às práticas populares e ancestrais de saúde e de busca de respostas coletivas para as questões de saúde reúnem processos capazes de incluir grupos da população com pouca ou nenhuma voz (Stotz, David e Wong Un, 2005).

Em 2009, o Ministério da Saúde instituiu, por meio da portaria n. 1.256, de 17 de junho, o Comitê Nacional de Educação Popular em Saúde (CNEPS), 
espaço colegiado com a participação de representantes da gestão do SUS e dos movimentos populares cujo objetivo principal é participar da formulação, acompanhamento à implementação e à avaliação da Política Nacional de Educação Popular em Saúde no SUS (PNEPS-SUS). Partiu-se para a realização de um conjunto de encontros regionais em todo o país para buscar, nas bases populares, os elementos constitutivos da PNEPS. Como política instituída, a portaria que descreve a PNEPS-SUS foi publicada somente em 29 de julho de 2013, por meio da portaria ministerial n. 2761, e traz como princípios os conceitos de diálogo, amorosidade, construção compartilhada do conhecimento, a problematização da realidade e o sentido emancipatório das práticas educativas (Brasil, 2013).

No período entre 2010 e 2015, outras iniciativas no campo da Educação Popular foram também apoiadas pela SGEP. Como exemplo, pode-se citar o Curso de Educação Popular em Saúde (EdpopSUS), voltado para agentes comunitários de saúde e agentes de endemias, além do apoio à instalação das Tendas Paulo Freire, espaços de diálogo e troca, em diversos eventos acadêmicos da área da saúde.

O Curso FHP nasce de diálogos e reflexões acerca da importância da formação política de graduandos e das indagações de docentes e pesquisadores acerca das possibilidades de se instaurar processos formativos com esse caráter dentro da grade curricular, como atividade de extensão. Os docentes e pesquisadores que teceram as primeiras reflexões a respeito dessa formação são do Rio de Janeiro, especificamente da Faculdade de Enfermagem da Universidade do Estado do Rio de Janeiro (UERJ) e da Escola Nacional de Saúde Pública Sérgio Arouca (ENSP), da Fundação Oswaldo Cruz.

$\mathrm{O}$ primeiro desenho do curso foi apresentado à SGEP por meio de um projeto para convênio, entre UERJ e MS, em 2012, já indicando a parceria com a ENSP-Fiocruz. Firmado o convênio e iniciada sua execução em meados de 2013, partiu-se para o planejamento inicial das atividades. Ocorre que, nesse meio tempo, conversas entre docentes e pesquisadores de outras Instituições de Ensino Superior (IES), públicas e privadas, de vários estados do país, evidenciaram que a necessidade de um curso nesses moldes não era exclusiva das IESs do Rio de Janeiro. Juntamente com a possibilidade de ampliar o número de IESs e docentes participando da elaboração da proposta, surgiu, naturalmente, afinada com a perspectiva da Educação Popular e Saúde, a ideia de compartilhamento de saberes.

A construção da proposta e o desenvolvimento do Curso para a Formação Histórica e Política de Estudantes Universitários da Área da Saúde orientou-se pelo princípio da construção coletiva e compartilhada com professores das IESs nos estados, tendo, ainda, a integração de estudantes e participantes de movimentos sociais, especialmente vinculados à educação popular e saúde. Para tal, 
foram realizadas três oficinas: as duas primeiras, em outubro e novembro de 2013, resultaram na construção do Projeto Político-Pedagógico, da identidade visual, das diretrizes para elaboração do material didático-pedagógico e do Ambiente Virtual de Aprendizagem (AVA), bem como na formação da equipe de coordenação geral do curso. A terceira oficina, realizada em dezembro de 2014, teve como objetivo principal promover uma avaliação da primeira edição do Curso FHP, além de traçar e definir orientações para elaboração de materiais educativos com a produção do curso.

A primeira edição do Curso FHP ocorreu de setembro a novembro de 2014 e ofereceu um total de 1.274 vagas, distribuídas entre 23 IESs, em 13 estados mais o Distrito Federal (Quadro 1). Foram 1.000 vagas para estudantes universitários da área da saúde, matriculados na IES para qual efetuaram sua inscrição, e 274 vagas adicionais para outros perfis, tais como: participantes de projeto de extensão universitária, alunos de pós-graduação, profissionais da saúde, alunos dos cursos técnicos e participantes dos movimentos sociais e de trabalhadores.

\section{Quadro 1}

\begin{tabular}{|c|c|}
\hline Estado & Instituição de Ensino Superior \\
\hline Alagoas & $\begin{array}{l}\text { Universidade Federal de Alagoas - Faculdade de Medicina - Núcleo de Saúde Pública/ Laboratório de } \\
\text { Educação Popular }\end{array}$ \\
\hline Bahia & $\begin{array}{l}\text { Universidade Federal da Bahia - Instituto de Humanidades, Artes e Ciências - Bacharelado } \\
\text { Interdisciplinar em Saúde }\end{array}$ \\
\hline Ceará & Universidade do Estado do Ceará - Centro de Ciências da Saúde - Curso de Enfermagem \\
\hline Distrito Federal & $\begin{array}{l}\text { Escola Superior de Ciências da Saúde } \\
\text { Universidade de Brasília (UnB) }\end{array}$ \\
\hline Goiás & Universidade Federal de Goiás - Faculdade de Enfermagem e Faculdade de Odontologia \\
\hline Minas Gerais & Universidade Federal de Minas Gerais - Núcleo de Estudos Trabalho \& Educação \\
\hline Paraíba & $\begin{array}{l}\text { Universidade Federal da Paraíba - Pró-Reitoria de Extensão e Assuntos Comunitários - Coordenação } \\
\text { de Educação Popular (COEP) - Centro de Ciências da Saúde - Departamento de Promoção da Saúde; } \\
\text { Departamento de Fisioterapia, Departamento de Fonoaudiologia e Departamento de Enfermagem } \\
\text { Clínica }\end{array}$ \\
\hline Pernambuco & Universidade Estadual de Pernambuco - Núcleo Integrado de Saúde Coletiva \\
\hline Piauí & $\begin{array}{l}\text { Universidade Federal do Piauí (Campus Senador Helvídio Nunes de Barros - Picos) - Bacharelado em } \\
\text { Enfermagem } \\
\text { Universidade Federal do Piauí (Campus Amílcar Ferreira Sobral - Floriano) - Bacharelado em } \\
\text { Enfermagem } \\
\text { Universidade Federal do Piauí (Campus Ministro Reis Veloso - Parnaíba) } \\
\text { Universidade Federal do Piauí - Centro de Ciências da Saúde/ Bacharelado em Medicina } \\
\text { Universidade Federal do Piauí - Centro de Ciência da Saúde/Bacharelado em Odontologia }\end{array}$ \\
\hline Rio de Janeiro & $\begin{array}{l}\text { Universidade do Estado do Rio de Janeiro - Faculdade de Enfermagem } \\
\text { Universidade do Estado do Rio de Janeiro - Instituto de Nutrição } \\
\text { Universidade Federal Fluminense - Instituto de Saúde da Comunidade - Departamento de } \\
\text { Planejamento em Saúde e Departamento de Saúde e Sociedade } \\
\text { Universidade Federal do Rio de Janeiro (Campus Macaé) - Curso de Licenciatura em Ciências } \\
\text { Biológicas, Curso de Enfermagem e Obstetrícia e Curso de Nutrição } \\
\text { Universidade Federal do Rio de Janeiro (Campus Fundão) - Instituto de Estudos em Saúde Coletiva e } \\
\text { Faculdade de Medicina } \\
\text { Faculdade Arthur Sá Earp Neto - Faculdade de Medicina }\end{array}$ \\
\hline & Universidade Centro Universitário Augusto Motta - Curso Bacharel em Enfermagem \\
\hline
\end{tabular}


Continuação Quadro 1

Instituições de Ensino Superior participantes do Curso Formação Histórica e Política

Rio Grande do Sul Universidade Federal do Rio Grande do Sul - Escola de Enfermagem e Curso de Bacharelado em Saúde Coletiva

Santa Catarina Universidade Federal de Santa Catarina - Centro de Ciências da Saúde - Departamento de Nutrição Universidade do Planalto Catarinense - Pró-Reitoria de Pesquisa, Extensão e Pós-Graduação (Curso de Enfermagem, Curso de Medicina e Curso de História)

Universidade do Vale do Itajaí - Curso de Pós-Graduação em Saúde e Gestão do Trabalho

Universidade Comunitária da Região de Chapecó - Programa de Mestrado em Políticas Sociais, Dinâmicas Regionais e em Ciências da Saúde; Curso de Psicologia e Curso de Enfermagem

São Paulo Universidade de São Paulo (Campus Ribeirão Preto) - Escola de Enfermagem de Ribeirão Preto e Faculdade de Medicina de Ribeirão Preto

Universidade de São Paulo (Campus São Paulo) - Departamento de Enfermagem em Saúde Coletiva Universidade Federal de São Carlos - Departamento de Metodologia de Ensino, Departamento de Medicina, Programa de Pós-Graduação em Educação, Departamento de Educação Física e Motricidade Humana, Unidade de Atendimento à Criança

Sergipe Universidade Federal de Sergipe - Departamento de Serviço Social, Departamento de Medicina, Departamento de Terapia Ocupacional, Departamento de Farmácia, Departamento de Enfermagem, Articulação Nacional de Movimentos e Práticas de Educação Popular e Saúde, Pró-Reitoria de Extensão Universidade Federal de Sergipe (Campus Lagarto) - Departamento de Educação em Saúde

Fonte: Os autores.

Efetuou-se a inscrição, seleção, divulgação dos resultados e matrícula, de abril a agosto de 2014. O processo de seleção seguiu os critérios definidos por cada IES, dentre esses a análise da carta de intenção que consistia na resposta à pergunta: "Qual a sua motivação para fazer este curso?".

O Curso FHP recebeu um total de 2.471 candidatos inscritos. Foram selecionados 1.274 estudantes; destes, 990 realizaram a matricula, distribuídos em 59 turmas nas 23 IES. O Curso FHP contou com a participação de 106 professores/mediadores, incluindo a coordenação geral, e certificou 251 concluintes $(25 \%$ do total de matriculados) que atenderam aos requisitos exigidos para certificação.

\section{Projeto Político-Pedagógico do Curso FHP}

O objetivo geral do Curso FHP foi o de iniciar o estudo da sociedade em que vivemos, com vistas à sensibilização e compreensão, pelo estudante e profissional, do contexto das políticas e da defesa dos direitos sociais e do SUS.

O termo 'formação' foi problematizado e questionado, pois, a rigor, o curso, na modalidade de extensão e semipresencial, não pretendeu conduzir um processo formativo, no sentido mais amplo do termo. No entanto, a ideia de denominá-lo como 'capacitação' ou 'reflexão' também não pareceu aderir aos objetivos do curso e, ao final, optou-se por manter o termo inicial. Esta opção busca, também, demarcar uma concepção que rompe com a ideia tradicional e mais difundida (e mais restrita) de formação como processo operacional, técnico e subproduto do sistema educacional. Esta alternativa é, portanto, parte de um debate mais profundo e crítico sobre a relação educação-trabalho, numa perspectiva de resgate da positividade do trabalho, na qual o ser hu- 
mano pode criar e ser recriado, não apenas trabalhar para sobreviver (Cattani e Spindula, 2006).

Os objetivos específicos referem-se à organização modular do curso: três módulos principais, intercalados com momentos presenciais e aulas e fóruns de discussão no AVA, conforme programa de estudos apresentado no Quadro 2.

Quadro 2

Curso formação histórica e política de estudantes universitários da área da saúde: programa de estudos segundo o módulo objetivo, aulas e atividades

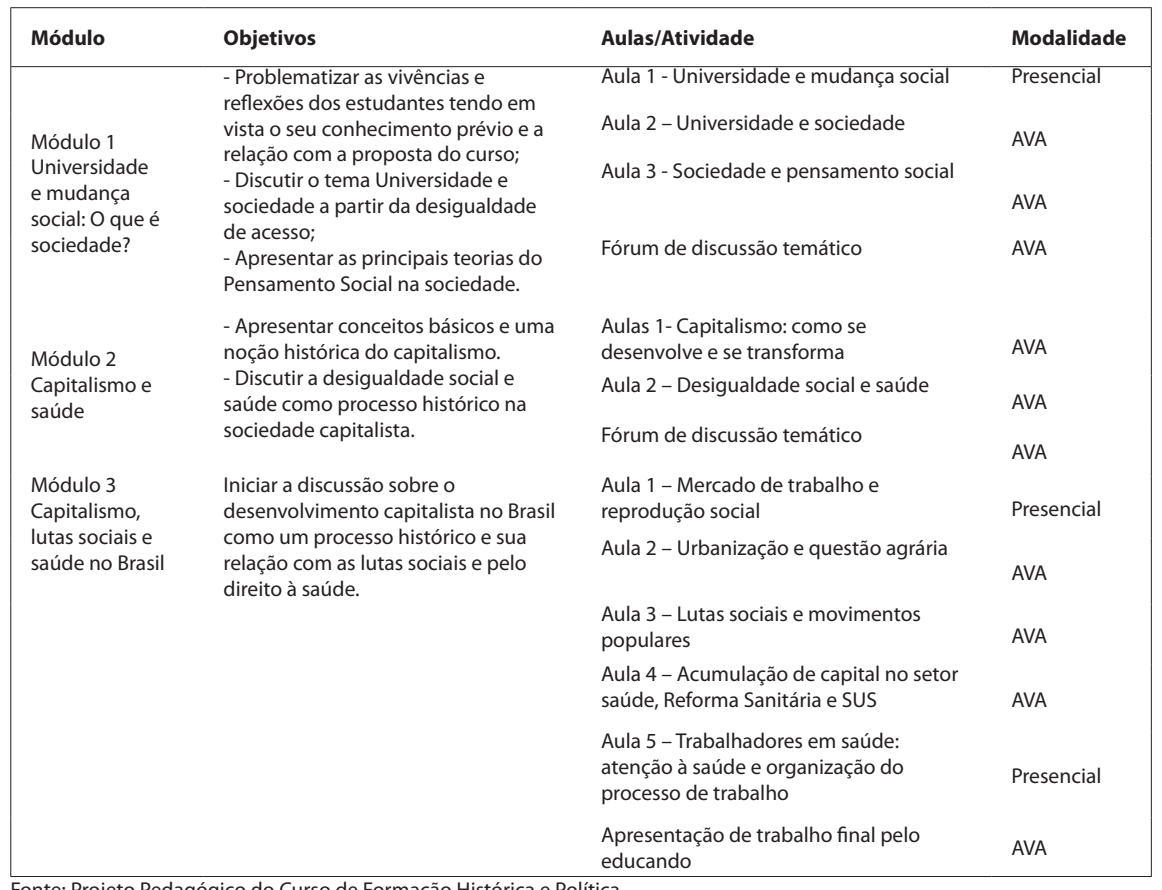

Fonte: Projeto Pedagógico do Curso de Formação Histórica e Política.

Nota: AVA - Ambiente Virtual de Aprendizagem.

Partir da prática vivenciada pelos estudantes, problematizando-a e interpretando-a, para retomá-la de modo compreensivo significa considerar a inserção desses discentes na universidade, com suas motivações e expectativas. Além disso, estimula-se a apreensão do papel desta instituição no contexto atual, considerando as contradições que movem esta sociedade e os interesses em disputa no seu interior, bem como as representações e teorias que se propõem a construir uma visão acerca desta comunidade.

A organização do curso sob a forma modular considerou três grandes temas geradores - educação, trabalho e saúde - que expressam a apreensão e a problematização da prática de inserção dos estudantes envolvidos no curso de iniciação ao estudo da sociedade brasileira.

O que se buscou nesse processo pedagógico, caracterizado pela dialética prática-teoria-prática, foi desenvolver a autonomia de pensamento, o interesse de pesquisa e a reflexão crítica, tanto individual como coletivamente, 
sobre os contextos e processos de vida na sociedade nos quais os estudantes estão inseridos.

Do ponto de vista didático-pedagógico, a dialética prática-teoria-prática foi vivenciada em aulas presenciais e no AVA considerando cinco quesitos que serão explicitados a seguir. O primeiro refere-se ao questionamento, à reflexão e ao debate sobre a prática de inserção dos estudantes em momentos presenciais. O segundo trata da sistematização desse momento de modo teórico-conceitual nas aulas estruturadas no AVA. O terceiro quesito diz respeito à realização de exercícios individuais para aprendizagem no ambiente virtual enquanto o quarto item aborda a discussão dos conteúdos, exercícios e questões por meio dos fóruns de discussão no AVA. O quinto item está relacionado à elaboração de um trabalho final que expresse, individual e coletivamente, por turmas, o que e como se aprendeu.

A carga horária total do curso foi de 60 (sessenta) horas, integrada de atividades teóricas e práticas, com momentos presenciais (doze horas) e no AVA (quarenta e oito horas).

O Curso FHP foi realizado de modo descentralizado nas IES dos estados, integrado pelo Projeto Político-Pedagógico e o acompanhamento feito pela coordenação geral. Este processo foi avaliado como mais adequado à dimensão nacional do curso, permitindo a participação mais ampla dos educandos e professores/mediadores, assim como a pluralidade de abordagens no estudo e sistematização dos temas.

A avaliação dos educandos foi conceitual, segundo as atividades realizadas no curso, especialmente nas aulas presenciais, nos fóruns de discussão no AVA e pela apresentação de um trabalho final.

Os concluintes do curso receberam o certificado expedido pela UERJ. Conforme o interesse, cada IES também emitiu um certificado próprio, a partir do registro do Curso FHP como projeto de extensão em sua instituição. Para ser certificado, o educando atendeu os seguintes requisitos, necessariamente: ter o mínimo de $75 \%$ (setenta e cinco por cento) de frequência, tanto nos encontros presenciais quanto no acesso ao AVA; participar dos fóruns de discussão no AVA e, por fim, apresentar o trabalho final.

\section{Material didático-pedagógico}

Com base nas diretrizes do projeto político-pedagógico, a elaboração do material didático partiu da prática vivenciada pelos estudantes de graduação e conflitos na sociedade brasileira como elementos disparadores para a problematização e a reflexão dos temas das aulas.

Com o intuito de empregar linguagem acessível para despertar o interesse dos estudantes, o curso utilizou diversos recursos em diferentes mídias, como 
charges, tirinhas, vídeos, poemas, músicas, entre outros. Cada aula contou com um texto-base para aprofundamento de seu respectivo tema.

O módulo 1, intitulado Universidade e Mudança social, constou de três aulas. A primeira aula (presencial) teve como objetivo problematizar as vivências e reflexões dos estudantes levando em conta seu conhecimento prévio. Para tal, foi desenvolvida a partir da pergunta: Qual o papel da universidade na sua vida, na vida das pessoas e na sociedade?

Em seguida, foi destacado, na aula 2, o processo de escolarização, bem como valores e conflitos sociais. Para tal, buscou-se a temática da desigualdade no que se refere ao ingresso à universidade por meio da estratificação social. $\mathrm{O}$ acesso a profissões melhor remuneradas e de elevado prestígio social estão relacionadas ao maior nível de preparação e renda das famílias.

Diferentes interpretações acerca da desigualdade de acesso à escolarização integral estão presentes na sociedade e entre os jovens, segundo o grupo, camada ou classe social, em determinado contexto histórico. Algumas dessas diferenças foram examinadas com aporte do estudo Valores atribuídos ao trabalho e expectativa de futuro: como os jovens se posicionam?, de Lachtim e Soares (2011). Também foi possível problematizar a ideia de ascensão social vinculada à 'escolarização', entendida como um processo institucionalizado de sistematização e de ensinamento e aprendizagem dos saberes existentes. Desse modo, são formados diversos tipos de sujeitos, de acordo com as necessidades e exigências da sociedade, em um momento de seu desenvolvimento, como escreve Carlos Rodrigues Brandão (2007), principal referência e textobase desta aula.

Essa reflexão trouxe a problematização da natureza da própria sociedade, tema da aula 3, Sociedade e pensamento social. Ou seja, a universalização da educação escolar é um fato social. E todo fato social é histórico e provoca diferentes valores, mas há algo mais: numa sociedade dividida socialmente, não há consenso em torno dos valores nem das teorias (explicações) sobre os fatos sociais.

Esta aula apresentou brevemente as concepções fundamentais de mundo em que se dividem as interpretações da realidade e das práticas na sociedade, quais sejam: a conservadora, a liberal e a socialista. A aula tomou como fato histórico as manifestações ocorridas no Brasil entre junho de 2013 e janeiro de 2014, a partir da luta contra os aumentos nas tarifas e o direito ao transporte público e os chamados 'rolezinhos', por meio de textos publicados em veículos de imprensa e redes sociais (Coutinho, 2013; Trindade e Filgueiras, 2013; Rosenfield, 2014) para analisar as ideias principais de cada uma das três concepções, apoiada em O que é Sociologia?, de Carlos Benedito Martins (2007).

Um dos aspectos destacados na aula foi a dificuldade em identificar, na tradição do pensamento social brasileiro, o liberalismo e o conservadorismo 
'puros'. Da mesma forma, entre os socialistas há diferenças, por exemplo, acerca da compreensão da democracia, entendida por alguns como valor universal, ou como valor histórico, por outros (Stotz, 2014).

Assim, conclui-se a aula e com ela o primeiro módulo: entender o que é, como se desenvolve uma sociedade e quais são as alternativas para seu futuro. Isso significa posicionar-se numa disputa no plano das ideias que tem, no final das contas, diante dos conflitos sociais, um sentido político concreto.

No segundo módulo, Capitalismo e saúde, a primeira aula foi intitulada Capitalismo: como se desenvolve e se transforma. Tomou-se, como ponto de partida, o fato de que o crescimento da renda, entre 2005 e 2013 no Brasil, tenha sido apresentado como fator de redução da desigualdade social pela ascensão das pessoas para a chamada 'classe C' ou a 'nova classe média'. Isso, no sentido de problematizar a desigualdade social na sociedade capitalista segundo a abordagem da estratificação social por renda (subjacente à maioria das interpretações da 'Classe $C^{\prime}$ ) e pela abordagem das classes sociais. Seguindo por esta última, de perspectiva crítica, apresentaram-se conceitos básicos (classes sociais, exploração do trabalho e resistência dos trabalhadores, Estado), a partir do exemplo histórico das lutas pela redução da jornada de trabalho e uma noção histórica do capitalismo cujo entendimento se faz à luz das teorias construídas no seu próprio processo de desenvolvimento.

Na segunda aula desse módulo, Desigualdade social e saúde, foram apresentados quatro exemplos de desigualdade social e saúde. O primeiro refere-se à mortalidade por grupos de causa e diferenciais de mortalidade entre classes sociais; o segundo exemplo diz respeito a dois exemplos extraídos de Laurell (1981). O terceiro é relativo à mortalidade antes dos dois anos de idade (Behm, 2011). O quarto exemplo problematiza a distribuição dos coeficientes de mortalidade infantil (e seus componentes), na cidade de Ribeirão Preto-SP (Almeida et al., 1992). A opção de trazer exemplos de estudos identificados com a abordagem clássica da medicina social latino-americana, que, no Brasil, assumiu o nome de Saúde Coletiva, teve o intuito de introduzir a perspectiva da determinação histórica e social do processo saúde-doença na sociedade capitalista (Breilh, 2013).

Ainda na caracterização do modo de produzir histórica e socialmente a doença, na atualidade, foi utilizado o caso da gripe suína (H1N1), doença que emerge nas precárias condições sanitárias da produção intensiva de porcos em uma grande empresa transnacional do ramo alimentício instalada no México. Na aula, a problematização desse tema apoiou-se nos vídeos Gripe suina: como, $e$ de onde veio?, Parte 1 e Parte 2 (2009). Esse caso suscitou reflexões sobre a produção agroindustrial de alimentos e seus riscos para a saúde.

Com base nesses casos e estudos, os materiais da aula apontam que as classes trabalhadoras adoecem e morrem mais por todos os grupos de causas que as demais. A sociedade capitalista responde por um modo específico de 
produção social de desgaste dos trabalhadores historicamente determinado, expresso em adoecimento, acidentes, agravos, morte, sofrimento e mal-estar. Esses acontecimentos concretizam-se em distintos perfis epidemiológicos conforme o grupo. Ou seja, de acordo com a inserção nos sistemas produtivos, na forma de distribuição da riqueza e na organização social do trabalho.

A compreensão diferenciada do processo saúde-doença também está radicada nas práticas dos grupos, frações e classes sociais e seus conflitos, e não apenas nas condições de vida e no consumo de serviços médicos ou de saúde. Os efeitos destas práticas expressos em valores, crenças, sentidos e significados implicam negativa ou positivamente no processo saúde-doença, pois integram perspectivas legitimadoras ou questionadoras das relações de exploração e dominação na sociedade. Assim, tanto a aula quanto o módulo 2 foram finalizados.

O terceiro e último módulo, Capitalismo, Lutas sociais e Saúde no Brasil, teve início com a aula Mercado de trabalho e reprodução social (presencial). Nela, foram recuperados os conteúdos anteriores e introduzida a discussão acerca da reprodução social a partir das informações sobre a estrutura do mercado de trabalho brasileiro (empregador, empregado com ou sem carteira, empregados domésticos, por conta própria, militares e funcionários públicos, desempregados). Tais informações são provenientes da Pesquisa Nacional por Amostra de Domicílios - 2003 e 2012 (Instituto Brasileiro de Geografia e Estatística, 2003; 2012).

Nas aulas 2 e 3, Urbanização e questão agrária e Lutas sociais e movimentos populares, respectivamente, os educandos foram provocados a refletir acerca da desigualdade estrutural e histórica do campo e das cidades brasileiras. Tal reflexão ocorreu a partir de exemplos atuais das questões agrária e urbana, como o chamado agronegócio e a segregação social nas cidades e suas implicações para o ambiente, para a saúde e para a vida dos trabalhadores. Os conflitos no campo e na cidade também foram apresentados como expressão da luta por direitos sociais na constituição de vários movimentos populares em diferentes momentos históricos, tais como: Movimento Popular de Saúde, Sindicatos, Movimento dos Trabalhadores Rurais Sem-Terra (MST), Movimento dos Trabalhadores Sem-Teto (MTST), Movimento Passe Livre (MPL).

A aula 4 - Acumulação de capital no setor saúde, Reforma Sanitária e SUS -, teve o propósito de discutir o processo histórico de luta pelo direito social à saúde, com base nos eixos discriminados a seguir. Primeiramente, como se organizou historicamente a atenção à saúde no Brasil; em seguida, de que modo o sistema de saúde tornou-se um meio para acumulação de capital. Numa terceira etapa, discutiu-se como a crise desse sistema nos anos 1970-80 abriu caminho para a luta pelo direito à saúde e às propostas reformistas na saúde que conduziram ao SUS. Em consecução, analisou-se a importância da participação popular com movimentos de resistência na saúde, que incluiu, 
a título de ilustração, os movimentos de Luta Antimanicomial, a Frente Nacional Contra a Privatização da Saúde, o movimento estudantil da área da saúde, entre outros.

A última aula, Trabalhadores em saúde, de caráter presencial, problematizou os conflitos entre a organização dos 'serviços de saúde' e a conquista do direito à saúde. Os primeiros viabilizam o consumo de equipamentos médicos, medicamentos e insumos de saúde pelo complexo médico-industrial da saúde, com ênfase na doença. Já a conquista do direito à saúde ultrapassa os serviços e o setor saúde. O debate entre estudantes e professores-mediadores na aula de encerramento do Curso FHP pautou-se pela seguinte questão: De que forma trabalhadores e estudantes na área da saúde podem contribuir com as transformações necessárias para a efetivação do direito à saúde?

$\mathrm{Na}$ conclusão do curso, os educandos foram convidados a responder individualmente aos seguintes questionamentos: O que e como aprendi? Como o aprendizado do curso está refletindo ou poderá refletir em minha prática estudantil e profissional? Vale ressaltar que a análise mais detalhada do conteúdo destas respostas não integra o material que dá origem ao presente artigo e deverá passar por tratamento analítico mais apurado.

O material didático representou um guia introdutório e possuiu grande importância na sustentação do curso, preservada a autonomia pedagógica dos professores-mediadores para trazer exemplos, casos, ilustrações da realidade local como elemento-chave para sensibilização, envolvimento e reflexão pelos educandos e professores.

Vale destacar ainda que, de maneira complementar ao material didático e visando apoiar o processo pedagógico, criou-se uma página do curso na rede social Facebook (https://www.facebook.com/fhpeus) em que, durante seu desenvolvimento, eram postados outros materiais relativos ao tema de cada aula, os quais os estudantes podiam interagir entre si e com os educadores em um ambiente virtual largamente utilizado no cotidiano.

\section{Para concluir, contribuições e questões}

Destacam-se dois elementos fundantes do processo de construção e implementação do Curso FHP: a construção coletiva do conteúdo e a metodologia proposta.

O conceito de construção compartilhada é apresentado como uma formulação metodológica, na qual "a dinâmica e o processo de conhecimento produzido vão demarcando o caminho conceitual e teórico em função da realidade e da prática estabelecida" (Carvalho, Acioli e Stotz, 2001, p. 101). Nasce de uma experiência de pesquisa iniciada na segunda metade da década de 
1980, na Fundação Oswaldo Cruz, com o objetivo de desenvolver uma maior participação dos moradores do território estudado no processo de pesquisa.

Do ponto de vista epistemológico, essa ideia pretende destacar o valor de um conhecimento que se produz a partir da relação entre saberes diversos e entre o conhecimento científico e o do senso comum. Contrapõe-se à ideia de manutenção da assimetria entre saberes como expressão de relações de poder. O reconhecimento da diversidade de saberes não acarreta, necessariamente, uma hierarquização dos mesmos do ponto de vista cognitivo, embora remetam a diferentes dimensões e abordagens da realidade.

Assim, além de docentes e pesquisadores das diversas IESs que se agregaram à proposta do curso, buscou-se trazer pessoas inseridas nos movimentos sociais articulados aos professores e grupos de pesquisa nas IESs como forma de romper com um possível viés meramente acadêmico na elaboração do material. Ao mesmo tempo, a identidade visual foi tratada como elemento importante para o processo de comunicação e as ferramentas tecnológicas de educação à distância, sob a responsabilidade de equipe específica, também foram trazidas como aspectos relevantes. As oficinas de construção integraram, portanto, atores diversos, que trouxeram seu conhecimento específico, no que tange aos aspectos técnicos, tecnológicos e científicos, mas que também se sentiram convocados, ética e politicamente, a colaborar para que o processo ocorresse de forma efetivamente coletiva.

A avaliação dos resultados do curso foi elaborada em dois momentos distintos, que levantaram importantes questões para a análise do processo, as quais serão desenvolvidas a seguir. O primeiro momento referiu-se à análise inicial dos trabalhos finais, elaborados pelos educandos, tendo sido realizada pela coordenação nacional do curso. A segunda etapa foi representada pela oficina nacional de avaliação, a qual reuniu professores e pesquisadores das IESs participantes. Na prática, estes dois momentos aconteceram de maneira integrada, uma vez que a discussão na oficina de avaliação foi subsidiada pela apresentação da análise dos trabalhos finais dos educandos.

A leitura dos trabalhos finais indicou que o curso foi reconhecido pelos estudantes como instigante, tanto pelos temas e conteúdos quanto pela forma de sua abordagem. Houve uma percepção de que, de um modo geral, os temas abordados no curso não são contemplados na sala de aula das universidades, reafirmando a fragilidade da formação histórica e política das graduações na área da saúde.

A proposta de provocar reflexões que estimulem uma compreensão mais crítica sobre a sociedade em um processo de aprendizagem ativo foi destacada como ponto positivo, como aponta o trecho a seguir, de um dos trabalhos: 
“Nota-se que o curso trouxe uma aprendizagem de não permanecer no imediato (...) na busca do conhecimento da sociedade que vivemos (...) despertando um olhar investigativo no aluno".

Neste sentido, um aspecto destacado pelos estudantes foi a contribuição do curso na direção de uma tomada de posição política para atuação profissional na saúde e, mais amplamente, na sociedade. Foi possível notar que esta tomada de posição política passou também por questionamentos à formação em saúde, uma vez que reflexões desta natureza estiveram presentes no trabalho final. A diversidade proporcionada pelas trocas entre diferentes abordagens e olhares foi apontada como um dos aspectos que contribuiu bastante para estes questionamentos.

De um modo geral, para educandos e professores-mediadores, a experiência de participar do curso evidenciou a necessidade de se fortalecer a dimensão política da formação em saúde. Na oficina de avaliação, foi apontado que o curso provocou não somente questionamentos pelos estudantes, como também despertou reflexões dos professores-mediadores e pesquisadores, desencadeando, em algumas instituições, discussões internas sobre como incorporar as temáticas e reflexões propostas pelo curso nos programas de ensino e em suas atividades. Entende-se que, nestes casos, o curso veio a somar às reflexões que já vinham sendo feitas nas instituições e nos movimentos estudantis e sociais locais.

Na oficina de avaliação, foram consideradas as iniciativas, em diversos formatos, desdobradas a partir do desenho do curso, com criações e apropriações pelas equipes nas IESs. Exemplos de iniciativas: projetos de extensão; atividades de ensino como disciplina eletiva aberta a todos os cursos, grupo de estudo; organização de debates da conjuntura; fortalecimento da integração com extensão popular e os movimentos sociais e dos trabalhadores.

Foi possível constatar também que o curso se desenvolveu de maneira mais proveitosa em instituições onde havia grupos mais consolidados, de pesquisa ou extensão, nos quais estudantes e professores já faziam debates e ações próximas às temáticas do curso. Nestas instituições, o curso pode complementar as reflexões teóricas desenvolvidas nestes espaços, inserindo-se, por meio da mediação dos professores, em processos de aprendizagem com trocas e articulação de ações em andamento. Na mesma medida, o processo de planejamento, organização e acompanhamento dos educandos no desenvolvimento do curso também foi potencializado pela existência destes grupos.

Outro aspecto destacado nos trabalhos finais e na oficina de avaliação foi a proposta metodológica. As inovações pedagógicas, os conteúdos, linguagens, encadeamento dos temas e a clareza dos objetivos de aprendizagem foram apontados como pontos positivos. Sobre isso, um dos estudantes comentou em seu trabalho final: [o curso] 
se apresentou de maneira distinta da tradicional, porém não esbarrando em modismos pós-modernos de uma educação desestruturada e aparentemente sem propósitos, trabalhando o pensamento autônomo dos estudantes, mas mesmo assim sendo os professores figuras mediadores de discussões e apresentando conteúdo expositivo.

A incorporação de diferentes linguagens e formas de conhecimento como música, filmes e documentários, poemas, figuras, charges foi reconhecida como diferencial para o processo de aprendizagem. Nesse sentido, a página de Facebook do curso destacou-se pelas postagens que buscavam relacionar essas diferentes formas de expressão artística com os temas do programa de estudos. Houve, portanto, o desenvolvimento da interface entre ciência e arte, formas de conhecimento distintas quanto à abordagem do real, unidas na educação dirigida para melhor formar profissionais da saúde.

$\mathrm{O}$ ambiente virtual de aprendizagem e a página no Facebook foram pensados de modo a complementar e ser complementado pelos encontros presenciais. A participação dos professores-mediadores na discussão e elaboração dos módulos e das estratégias para os encontros contribuiu para minimizar a fragmentação entre os módulos. Embora tenha garantido permeabilidade às questões locais de cada IES, solidificaram os encontros presenciais como estratégia fundamental de discussão das aulas realizadas no ambiente virtual.

Esses espaços de interação, formação e compartilhamento de saberes, à distância, presenciais, formais e informais, permitiram o fortalecimento da relação intra e interinstitucional nas atividades dos professores-mediadores. O curso, nessa perspectiva, configurou-se como espaço para aproximação e integração entre estudantes e professores-mediadores de diferentes áreas de conhecimento nas IESs, oportunizando uma boa experiência de troca entre os envolvidos.

Os resultados do curso permitem uma avaliação positiva ainda naquelas turmas cuja evasão foi maior, pois também nesses grupos ocorreu uma participação dos estudantes nos debates e reflexão crítica sobre as atuais relações na sociedade. Nesse sentido, o critério quantitativo não se constitui como principal elemento da avaliação, visto que os rebatimentos da formação daqueles que participaram ativamente são inúmeros, seja na relação com seus pares, seja na construção do conhecimento, na prática profissional e na vida.

Entre os desafios e dificuldades na execução e planejamento do curso, que inclusive contribuíram para a evasão, destaca-se a sua execução no segundo semestre de 2014, com calendários afunilados em virtude da realização da Copa do Mundo no Brasil e das eleições. Além disso, pelos mais variados motivos, havia diferenças significativas nos calendários das diversas IESs participantes, o que acarretou divergência de datas de início e término do 
curso entre alguns locais. Outros fatores podem ter contribuído para a alta taxa de evasão, tais como dificuldades tecnológicas, de acesso à internet e de tempo pessoal, tanto de estudantes como de mediadores, já que o curso foi um processo formativo extracurricular. A identificação das causas de evasão, no entanto, segue como uma indagação a ser devidamente pesquisada em uma oportunidade de oferta posterior do curso.

Já no que diz respeito às etapas de planejamento e manutenção do curso, são reconhecidos desafios que também as restringiram em alguma medida. Entre eles, o pouco tempo disponível para debate e validação dos materiais com os professores-mediadores, dada a limitação de recursos financeiros para viabilizar um maior número de encontros presenciais entre os professoresmediadores e o prazo para execução do projeto. Como consequência, a elaboração dos materiais didáticos acabou concentrada na coordenação nacional do curso, apoiada por alguns professores e pesquisadores das IESs participantes.

A pouca experiência e familiaridade de grande parte dos professores-mediadores com o ambiente virtual e a EAD também foi uma dificuldade reconhecida na oficina de avaliação do curso. Nessa ocasião, os presentes apontaram a relevância da produção do material do curso em formato que permita sua impressão e publicação digital. Desta maneira, é possível torná-lo disponível para subsidiar outros cursos ou para ser usado em outros processos formativos, conduzidos de forma autônoma pelas IESs ou pelos movimentos sociais.

\section{Colaboradores}

Todos os autores participaram igualmente, em todas as etapas, da produção do artigo.

\section{Financiamento}

O presente trabalho foi realizado com apoio do Ministério da Saúde, Secretaria da Gestão Estratégica e Participativa na Saúde, por meio do Convênio 774339/12 com a UERJ, e da Coordenação de Aperfeiçoamento de Pessoal de Nível Superior - Brasil (CAPES) - Código de Financiamento 001.

Resumen La graduación universitaria de las áreas de salud ha sido objeto de debate respecto a la necesidad de cambios curriculares en torno a los principios del Sistema Único de Salud, entre otros temas. Entre los desafíos señalados se encuentra la superación de la formación técnica y operativa, y la ampliación de la capacidad de reflexión crítica del aluno sobre las determinaciones históricas y políticas de la salud. El texto analiza el proceso de enseñanza aprendizaje desde una perspectiva crítica a partir del curso para la Formación Histórica y Política de Estudiantes de Grado de las Áreas de Salud, actividad de extensión desarrollada en la modalidad semipresencial a nivel nacional, con el apoyo de la Política Nacional de Educación Popular en Salud en el Sistema Único de Salud. En el presente artículo se analizó la experiencia vivida durante el curso que tuvo lugar entre marzo y diciembre del 2014. El desarrollo del curso se basó en la concepción teórica y metodológica de la construcción compartida del conocimiento, orientada por el campo de la Educación Popular y Salud. El artículo presenta: histórico y proceso de construcción del curso, proyecto político pedagógico, material didáctico pedagógico y contribuciones y cuestiones, men- 
cionando posibles especializaciones o derivaciones futuras en procesos formativos en el área de salud.

Palavras clave formación en salud; trabajo en salud; proyecto político pedagógico; directrices curriculares; sociedad y salud.

\section{Notas}

${ }^{1}$ Universidade do Estado do Rio de Janeiro, Faculdade de Enfermagem, Departamento de Enfermagem de Saúde Pública, Rio de Janeiro, RJ, Brasil.

$<$ helenalealdavid@gmail.com>

Correspondência: Universidade do Estado do Rio de Janeiro, Faculdade de Enfermagem, Boulevard 28 de Setembro 157, $7^{\circ}$ andar, CEP 20551-030, Vila Isabel, Rio de Janeiro, RJ, Brasil.

${ }^{2}$ Fundação Oswaldo Cruz, Escola Nacional de Saúde Pública Sergio Arouca, Centro de Estudos da Saúde do Trabalhador e Ecologia Humana, Rio de Janeiro, RJ, Brasil.

<augusto@ensp.fiocruz.br>

${ }^{3}$ Fundação Oswaldo Cruz, Escola Nacional de Saúde Pública Sergio Arouca, Rio de Janeiro, RJ, Brasil.

<stotz@ensp.fiocruz.br>

${ }^{4}$ Fundação Oswaldo Cruz, Escola Nacional de Saúde Pública Sergio Arouca, Rio de Janeiro, RJ, Brasil.

$<$ ivolimal@gmail.com>

${ }^{5}$ Fundação Oswaldo Cruz, Escola Nacional de Saúde Pública Sergio Arouca, Rio de Janeiro, RJ, Brasil.

$<$ laira.vasconcellos@gmail.com>

${ }^{6}$ Universidade Federal do Rio de Janeiro, Instituto de Estudos em Saúde Coletiva, Programa de Pós-Graduação em Saúde Coletiva, Rio de Janeiro, RJ, Brasil.

$<$ leovmattos@gmail.com>

${ }^{7}$ Fundação Oswaldo Cruz, Escola Nacional de Saúde Pública Sergio Arouca, Rio de Janeiro, RJ, Brasil.

$<$ lucasbs@gmail.com>

${ }^{8}$ Faculdade de Medicina de Petrópolis, Petrópolis, RJ, Brasil.

<norhansumar@gmail.com>

${ }^{9} \mathrm{O}$ termo 'flexneriano' é oriundo do relatório que ganhou o nome de seu autor, Abraham Flexner, um professor de ensino médico, que o elaborou, em 1910, a pedido da Fundação Carnegie, órgão financiador de atividades de ensino. O Relatório, que analisou 155 escolas de ensino médico, apresenta elementos que posteriormente orientaram uma padronização do ensino médico e de outras profissões da saúde, com recomendações de que estivessem inseridos em universidades, tivessem conteúdos teóricos e práticos, preferencialmente em um hospital universitário, com currículos organizados em disciplinas delimitadas às respectivas áreas de especialidade médica. As críticas a este modelo, cujos efeitos podem ser até os dias de hoje observados na maior parte dos cursos de graduação profissional em saúde, decorrem das dificuldades de articular teoria e prática e de integrar conteúdos e áreas disciplinares, isolando conteúdos (Unicamp, 2010). 


\section{Referências}

ALMEIDA, Luis Eduardo A. Social class and infant mortality in Ribeirão Preto, São Paulo. Cadernos de Saúde Pública, Rio de Janeiro, v. 8, n. 2, p. 190-198, abr.-jun, 1992.

ARAÚJO, Dolores; MIRANDA, Maria Claudina G.; BRASIL, Sandra L. Formação de profissionais de saúde na perspectiva da integralidade. Revista Baiana de Saúde Pública, Salvador, v. 31, n.1, p. 20-31, 2007.

BEHM, Hugo. Determinantes económicos y sociales de la mortalidad en América Latina. Salud Colectiva, Buenos Aires, v. 7, n. 2, p. 231-253, maio-ago. 2011.

BRANDÃO, Carlos R. O que é educação? São Paulo: Brasiliense (Coleção Primeiros Passos), 2007.

BRASIL. Lei n. 8.080, de 19 de setembro de 1990. Lei Orgânica da Saúde. Dispõe sobre as condições para a promoção, proteção e recuperação da saúde, a organização e o funcionamento dos serviços correspondentes e dá outras providências. Diário Oficial da República Federativa do Brasil, Poder Executivo, Brasília, DF, 20 set. 1990, Seção I, p. 18.055.

BRASIL. Ministério da Saúde. Portaria n. 1.256, de 17 de junho de 2009. Institui o Comitê Nacional de Educação Popular em Saúde (CNEPS). Diário Oficial da República Federativa do Brasil, Poder Executivo, Brasília , DF. Disponível em: <http://bvsms.saude.gov.br/ bvs/saudelegis/gm/2009/prt1256_17_06_2009. html>. Acesso em: 21 abr. 2017.

BRASIL. Ministério da Saúde. Ministério da Educação. Portaria Interministerial 421, de 3 de março de 2010. Institui o Programa de Educação pelo Trabalho para a Saúde (PET Saúde) e dá outras providências. Diário Oficial da República Federativa do Brasil, Poder Executivo, Brasília, DF, 5 mar. 2010.

BRASIL. Ministério da Saúde. Secretaria da Gestão Estratégica e Participativa na Saúde.
Portaria n. 2.761, de 19 de novembro de 2013. Institui a Política Nacional de Educação Popular e Saúde. Diário Oficial da República Federativa do Brasil, Poder Executivo, Brasília, DF, 20 nov. 2013.

BREILH, Jaime. La determinación social de la salud como herramienta de transformación hacia una nueva salud pública (salud colectiva). Revista Facultad Nacional de Salud Pública, Medellín, v. 31, supl. 1, p. 13-27, 2013.

CARVALHO, Maria Alice P.; ACIOLI, Sonia; STOTZ, Eduardo N. O processo de construção compartilhada do conhecimento: uma experiência de investigação científica do ponto de vista popular. In: VASCONCELOS, Eymard M. (org.). A saúde nas palavras e nos gestos: reflexões da rede de educacão popular e saúde. São Paulo: Hucitec, 2001. p. 101-114.

CATTANI, Antônio D.; SPINDULA, Brenda F. Formação humana (verbete). In: CATTANI, Antônio D.; HOLZMANN, Lorena (orgs.). Dicionário de trabalho e tecnologia. Porto Alegre: Ed UFRGS, 2006. p. 136-141.

COUTINHO, João P. 10 impressões sobre o Brasil. Folha de S. Paulo, 25 jun. 2013. Disponível em: <http://wwwl.folha.uol.com.br/ colunas/joaopereiracoutinho/2013/06/1300419dez-impressoes-sobre-o-brasil.shtml $>$. Acesso em: 21 abr. 2017.

FERNANDES, Josicelia D. et al. Aderência de cursos de graduação em enfermagem às diretrizes curriculares nacionais na perspectiva do sistema único de saúde. Escola Anna Nery Revista de Enfermagem, Rio de Janeiro, v. 17, n. 1, p. 82-89, 2013.

GRIPE SUÍNA: Como, e de onde veio? Produção, filmagem e edição de Nicoletti. Brasília: UNB TV, 2009. Disponível em: Parte $1<$ https:// www.youtube.com/watch? $\mathrm{v}=\mathrm{hB14yojw} \_-$ M> e Parte $2<$ https://www.youtube.com/ 
watch?v=pBwlhiDDccM $>$. Acesso em: 5 maio 2017.

INSTITUTO BRASILEIRO DE GEOGRAFIA E ESTATÍSTICA. Pesquisa nacional por amostra de domicílios (PNAD). Rio de Janeiro: IBGE, 2003.

INSTITUTO BRASILEIRO DE GEOGRAFIA E ESTATÍSTICA. Pesquisa nacional por amostra de domicílios (PNAD). Rio de Janeiro: IBGE, 2012.

LACHTIM, Sheila A. F.; SOARES, Cássia B. Valores atribuídos ao trabalho e expectativa de futuro: como os jovens se posicionam? Trabalho, Educação e Saúde, Rio de Janeiro, v. 9, n. 2, p. 277-294, out. 2011.

LAURELL, Asa Cristina. La salud-enfermedad como proceso social. Revista Latinoamericana de Salud, México, v. 2, n. 1, p. 7-25, 1981.

MARTINS, Carlos B. O que é Sociologia?. São Paulo: Editora Brasiliense, 2007.

ROSENFIELD, Denis L. Decifrando os rolezinhos. O Estado de São Paulo, São Paulo, 27 jan. 2014. Disponível em: <http://opiniao. estadao.com.br/noticias/geral, decifrandoos-rolezinhos-imp, 1123366>. Acesso em: 11 jun. 2017.

STOTZ, Eduardo N. Educação Popular e Saúde e democracia no Brasil. Interface: Comunicação,
Saúde, Educação, Botucatu, v. 18, supl. 2, p. 1.475-1.486, 2014.

STOTZ, Eduardo N.; DAVID, Helena M. S. L.; WONG UN, Julio A. Educação Popular e Saúde: trajetória, expressões e desafios de um movimento social. Revista APS, v. 8, n. 1, p. 90-112, 2005.

TRINDADE, José B. P.; FILGUEIRAS, Otto. A classe operária. Correio da Cidadania, São Paulo, 6 dez. 2013. Disponível em: <http:// correiocidadania.com.br/politica/9145-0612-2013-a-classe-operaria >. Acesso em: 20 abr 2017.

UNICAMP. Universidade de Campinas. Histórias de ensino superior: introdução ao relatório Flexner. Revista Ensino Superior UNICAMP, Campinas, v.1, n.1, p. 65-76, abr.2010. Disponível em: <http://www.gr.unicamp.br/ ceav/revistaensinosuperior/ed01_maio2010/ ed_01_maio2010_historias.php >. Acesso em: 12 jun. 2017.

VILELA, Elaine M.; MENDES, Iranilde José M. Interdisciplinaridade e saúde: estudo bibliográfico. Revista Latino-Americana de Enfermagem, Ribeirão Preto, v. 11, n. 4, p. 525-531, 2003.

Recebido em 29/06/2017. Aprovado em 13/09/2017.

\section{Errata}

Na página 1.012, artigo “CURSO PARA A FORMAÇÃO HISTÓRICO-POLÍTICA NA GRADUAÇÃO EM SAÚDE: ANÁLISE DE UMA CONSTRUÇÃO PARTILHADA", autoria de Helena Maria Scherlowski Leal David et al., com o DOI: 10.1590/1981-7746-sol00141, publicado no periódico Trabalho, Educação e Saúde, v. 16, n. 3, p. 997-1.015, incluiram-se os dados sobre o financiamento da pesquisa, em que se lê:

\section{Financiamento}

O presente trabalho foi realizado com apoio do Ministério da Saúde, Secretaria da Gestão Estratégica e Participativa na Saúde, por meio do Convênio 774339/12 com a UERJ, e da Coordenação de Aperfeiçoamento de Pessoal de Nível Superior - Brasil (CAPES) - Código de Financiamento 001. 